\title{
Enzymatic removal of cellulose from cotton/polyester fabric blends
}

\author{
Andreia Vasconcelos and Artur Cavaco-Paulo* \\ Department of Textile Engineering, Minho University, Guimarães, Portugal; *Author for correspondence \\ (e-mail: artur@det.uminho.pt; phone: +351-253-510271; fax: + 351-253-510293)
}

Received 7 November 2005; accepted in revised form 11 February 2006

Key words: Cellulase, Cellulose, Light-fabrics, Microfibrils, Polyester

\begin{abstract}
The production of light-weight polyester fabrics from a polyester/cotton blended fabric, by means of the enzymatic removal of the cellulosic part of the material, was investigated. The removal of cotton from the blended fabric yielded more than $80 \%$ of insoluble microfibrillar material by the combined action of high beating effects and cellulase hydrolysis. Other major features of this enzymatic process for converting cotton fibers into microfibrillar material are bath ratio, enzyme dosage and treatment time.
\end{abstract}

\section{Introduction}

Polyester dominates the world market for synthetic textile fibers (Aizenshtein 2004). Due to fashion tendencies there is a high demand for lightweight polyester fabrics that cannot be produced by standard power looms. One alternative production process is the manufacture of fabrics from polyester blended with another fiber that is subsequently removed by chemical treatments. The most common materials for this process are the polyester/cellulosic fiber blends in which the cellulose is normally removed with a $75 \%(\mathrm{v} / \mathrm{v})$ sulfuric acid solution. However, while the acid hydrolysis of cellulose is both fast and inexpensive, it has the drawback of being ecologically unfriendly. Enzymatic hydrolysis represents a cleaner alternative: it takes place at atmospheric pressure, moderate temperatures and mild $\mathrm{pH}$ conditions, resulting in a reduction of production costs, an increased environmental friendliness and an improved quality and functionality of the products (Camacho et al. 1996).
Many studies have been carried out with the aim of gaining an understanding of the mechanism of cotton hydrolysis. In nature, cellulose degradation is performed by cellulases of bacterial or fungal origin. The chemical composition of cellulose is very simple, consisting of glucose residues connected by $1,4-\beta$-glycosidic bonds. Nevertheless, the efficient degradation of this substrate requires the combined action of several types of cellulases (Tomme et al. 1995; Boisset et al. 2001; Murashima et al. 2002): endoglucanases (EC 3.2.1.4), which produce new ends randomly within the polysaccharide chain, cellobiohydrolases (EC 3.2.1.91), which release cellobiose units from the cellulose chain ends, and $\beta$-glucosidases (EC 3.2.1.21), which convert cellobiose into glucose (Tomme et al. 1995; Teeri 1997). The synergism among different types of cellulases is widely verified in the literature (Béguin 1990; Tomme et al. 1995; Clarke 1997; Teeri 1997). The accessibility of the fiber surface to the enzyme is a ratedetermining factor in the enzymatic hydrolysis (Mansfield et al. 1999). Cellobiohydrolases play 
an important role during cellulose degradation due to their specific three-dimensional structure (Boisset et al. 2001): the active site of these enzymes is enclosed by a peptide extension that covers the catalytic residues and produces a tunnel-like structure (Parsiegla et al. 1998); consequently, only the ends of a cellulose chain can access the active site. Conversely, endoglucanases produce internal cuts on the chain, releasing small cellulose fragments and providing new chain ends for the action of the cellobiohydrolases that are responsible for the degradation of the crystalline regions (Guimarães et al. 2002). Thus, cooperation between these two types of cellulases promotes the efficient and complete degradation of the microcrystalline cellulose, resulting in an enhanced extent of hydrolysis (Jeoh et al. 2002).

Trichoderma reesei is a well-known cellulolytic fungus and the subject of the most research carried out with respect to the production of cellulases for food and feed, pulp and paper and the textile industry. $T$. reesei secretes at least nine different endoglucanases and two different cellobiohydrolases (Foreman et al. 2003; Miettinen-Oinonen et al. 2005). The major cellobiohydrolase component of $T$. reesei is CBHI, which accounts for 50 $60 \%$ of the total amount of protein secreted (reviewed in Mäntylä et al. 1998; Penttilä 1998).

The research and application of cellulases in cellulosic materials aim at surface modification. Known applications are the removal of fuzz fibers or fibrillar material in textile processing and in domestic washing. Ageing effects, like the 'stonewashed' look, are also achieved with cellulases by means of 'superficial abrasion'. All of these effects can only be achieved in processes where strong mechanical agitation is present for short periods of treatment time, resulting in high levels of weight and strength loss (Morgado et al. 2000).

In the investigation reported here our objective was the total removal of the cellulosic part from a polyester/cotton blend to produce a light-weight polyester fabric using a crude cellulase mixture obtained from $T$. reesei.

\section{Experimental part}

\section{Enzyme and fabrics}

The enzyme used was a commercial crude cellulase from Trichoderma reesei, Cellusoft L, which was kindly provided by Aquitex, the Portuguese representative of Novozymes Biotech.

The cotton fabric used for the enzymatic treatments was a mercerized taffeta consisting of $100 \%$ cotton (54 ends $/ \mathrm{cm}, 30$ picks $/ \mathrm{cm}, 107 \mathrm{~g} / \mathrm{m}^{2}$ ). The blend was a taffeta mixture consisting of $66 \%$ cotton and $34 \%$ polyester ( 33 ends/cm, 25 picks/ $\mathrm{cm}, 128 \mathrm{~g} / \mathrm{m}^{2}$ ). Prior to the enzymatic treatments the fabric samples were washed with $2 \mathrm{~g} / \mathrm{l}$ of a non-ionic surfactant, Lutensol AT 20 (provided by BASF), in a domestic washing machine.

\section{Enzyme activity}

The protein content of cellulase was determined by the Bradford method (Bradford 1976). We first measured the enzymatic activity of Cellusoft L with soluble cellulose as the substrate: carboxymethylcellulose (CMC), the same amount of enzyme and the CMC solution was placed in a test tube for $30 \mathrm{~min}$ in a shaker bath at $50{ }^{\circ} \mathrm{C}$. The soluble reducing sugars released were then determined, as previously described by Cavaco-Paulo et al. (1996). The enzymatic activity of Cellusoft L on insoluble cellulose from cotton fabric was also measured, and expressed in terms of total weight loss. The cotton samples $(0.5 \mathrm{~g})$ were incubated for $1 \mathrm{~h}$ at $50{ }^{\circ} \mathrm{C}$ in a Rotawash machine $(20 \mathrm{rpm})$ with $1 \mathrm{~g} / 1$ of enzyme solution prepared in $0.1 \mathrm{M}$ acetate buffer, pH 5 (see Table 1).

\section{Enzymatic treatments}

All of the enzymatic treatments were carried out in a Rotawash machine $(20 \mathrm{rpm})$. Additional mechanical agitation was achieved by adding stainless steel discs $(20.0 \pm 0.1 \mathrm{~g}$ each disc) to the pots. The enzymatic treatments were carried out for varying lengths of incubation times and at different enzyme dosages prepared in $0.1 M$ acetate buffer, $\mathrm{pH} 5.0$, at $50{ }^{\circ} \mathrm{C}$. Each treatment was done in duplicate. Reference treatments were carried out under the same conditions but in the absence of the enzyme. To terminate the enzyme reaction, we added $2.5 \mathrm{ml}$ of $2 \% \mathrm{Na}_{2} \mathrm{CO}_{3}$ solution to the pots, following which the fabric samples were removed. The samples were then rinsed with $5 \% \mathrm{Na}_{2} \mathrm{CO}_{3}$ solution, followed by rinsing with hot and cold water. 
Table 1. Characterization of the cellulase, Cellusoft L, used in this investigation.

\begin{tabular}{lll}
\hline $\begin{array}{l}\text { Total } \\
\text { protein }(\mathrm{g} / \mathrm{l})\end{array}$ & $\begin{array}{l}\text { CMC activity } \\
(\mathrm{mg} / \mathrm{ml})\end{array}$ & $\begin{array}{l}\text { Cotton } \\
\text { activity }(\%)\end{array}$ \\
\hline $14.6 \pm 0.1$ & $25.8 \pm 0.3$ & $4.0 \pm 0.1$ \\
\hline
\end{tabular}

\section{Physical analysis}

The total weight loss of the samples was measured as the difference in the weight of the fabric sample before and after treatment, following sample conditioning for $24 \mathrm{~h}$ at $20^{\circ} \mathrm{C}$ and $65 \%$ relative humidity.

The insoluble weight loss was obtained after the filtration of the treatment solution. The filtrate was washed with hot and cold water in order to remove all of the reducing sugars and then dried at room temperature.

The bending length and flexural rigidity was determined using a fixed-angle flexometer as described in the 'International Standard ISO 90737:1995 Textile test methods for non-wovens - part 7: determination of the bending length'. The flexural rigidity is obtained from the bending length and the mass per unit area of fabric.

The breaking strength of samples was determined according to the 'Portuguese Standard NP EN ISO 13934-1:2001 Tensile properties of fabrics - part 1: determination of maximum force and elongation at maximum force using the strip method'. A fabric sample is strengthened at constant velocity until rupture. The sample should have a width of $50 \pm 0.5 \mathrm{~mm}$ and a length of $200 \mathrm{~mm}$. However, due to the dimensions of the treated samples, we used warp and weft yarns instead of a strip. Ten assays were performed on the warp and weft. The 'skeleton' is the term used for a sample from which all of the cellulose from the blend has been removed by acidic treatment. This sample was obtained as described in the international standard 'ISO 1833:1977 Textiles. Binary fiber mixtures - quantitative chemical analysis'. The sample was treated with $75 \%(\mathrm{v} / \mathrm{v})$ sulfuric acid solution at $50{ }^{\circ} \mathrm{C}$. This treatment was done in duplicate.

The scanning electronic microscopy (SEM) pictures were obtained in a scanning electronic microscope model LEICA S360 with a backscattered and secondary electron detector.

\section{Results and discussion}

\section{Treatment of $100 \%$ cotton fabric}

Cotton samples $(0.5 \mathrm{~g})$ were treated with different concentrations of Cellusoft L (10, 20, 100, 200, 400,800 and $1600 \mathrm{mg} / \mathrm{g}$ ). The treatments were performed in a Rotawash machine apparatus (Figure 4a), which provides vertical motion, and the additional mechanical effect was achieved by adding nine discs to each pot. The mechanical effects in a Rotawash machine are of three types (Cavaco-Paulo et al. 1996; Cavaco-Paulo 1998; Morgado et al. 2000) - fiber-fiber interfriction, fiber-metal interfriction and beating effects - all of which are due to gravitational forces during the vertical rotation of the treatment pots. The beating effects are increased by small bath ratios and by the presence of discs in the pots.

The results obtained here show that the high level of the beating effects enhanced enzymatic activity, thereby verifying the results reported by Cavaco-Paulo et al. (1996), Cavaco-Paulo (1998) and Morgado et al. (2000). These results are also supported by the treatments performed withand without discs. As shown in Figure 1, the weight loss increased from 7.5 to $100 \%$ in the presence of discs and $100 \mathrm{mg} / \mathrm{g}$ Cellusoft $\mathrm{L}$. The maximum weight loss was achieved $(100 \%)$ at an enzyme dosage of $100 \mathrm{mg} / \mathrm{gCellusoft} \mathrm{L}$; thus, the enzyme activity measured as weight loss remained constant. When the sample was treated without discs, the maximum weight loss obtained was $7.5 \%$, with an enzyme dosage of $200 \mathrm{mg} / \mathrm{g}$; the weight loss did not increase any further with increased enzyme dosage, indicating that saturation levels with respect to adsorption and hydrolytic attack on the fiber surface were reached.

The observed weight loss of the samples was achieved by the production of microfibrilar material (Figure 4b, c). A linear relationship was found between the number of discs and the increase in the total and insoluble weight loss (Figure 2). This linear relationship is due to the increased effects of the beating present in the vertical rotation of the pots (Morgado et al. 2000).Figure 3 shows SEM pictures of cotton samples treated with an enzyme dosage of $200 \mathrm{mg} / \mathrm{g}$ Cellusoft $\mathrm{L}$ for $1 \mathrm{~h}$ in the Rotawash machine at low (Figure 3b) and high (Figure 3c) levels of mechanical agitation. The sample treated without discs presented a fiber 


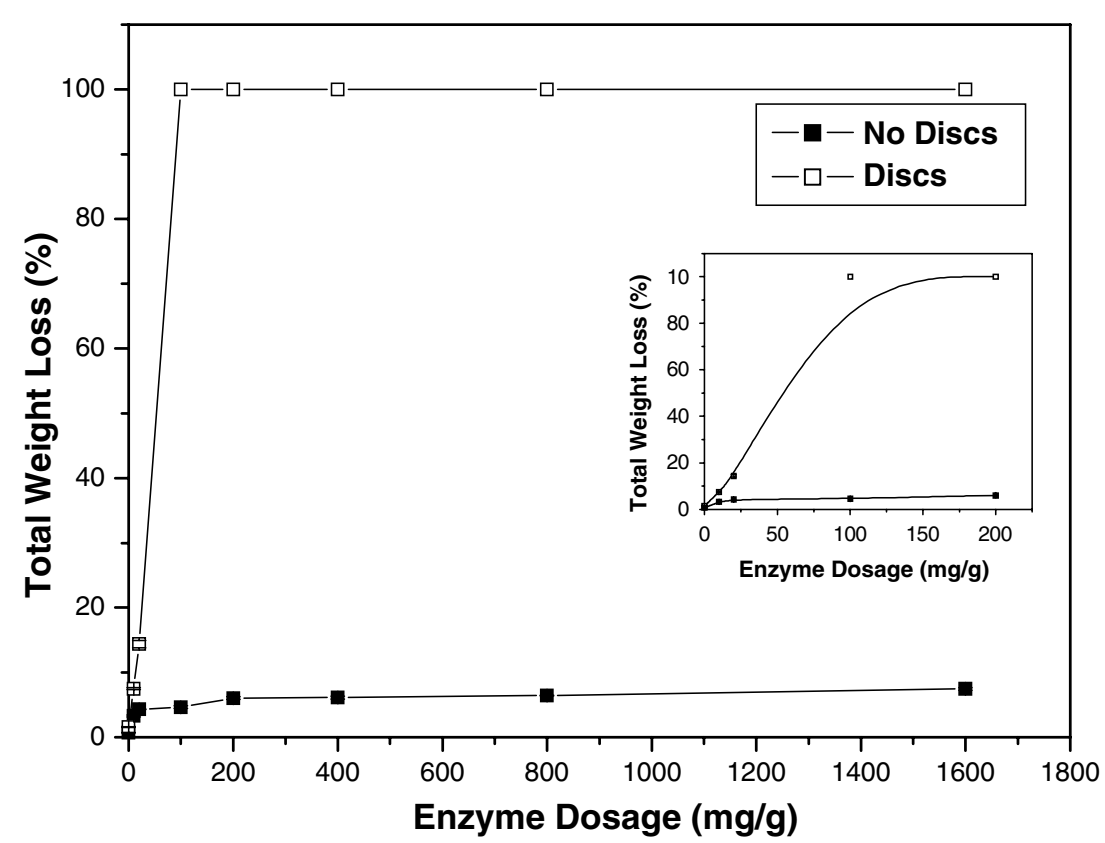

Figure 1. Variation in total weight loss (\%) of the fabric samples with the specified enzyme dosage $(\mathrm{mg} / \mathrm{g})$ after $2 \mathrm{~h}$ of treatment in a Rotawash machine at $50{ }^{\circ} \mathrm{C}$, with a bath ratio of $1: 200$, and with and without discs.

surface without degradation. When the level of mechanical agitation was increased, the fibers (Figure 3c) tended to defibrillate, yielding microfibrilar material (Figure 4c) with a consistent increase in insoluble powder.

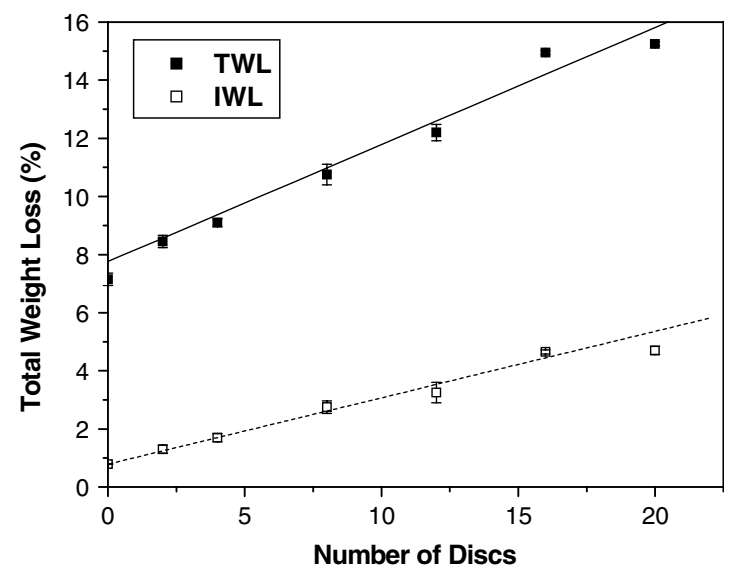

Figure 2. Variation in the total $(T W L)$ and insoluble $(I W L)$ weight loss of cotton samples as a function of the number of discs, after $2 \mathrm{~h}$ of treatment in the Rotawash machine at $50{ }^{\circ} \mathrm{C}$, with an enzyme dosage of $20 \mathrm{mg} / \mathrm{g}$ and a bath ratio of $1: 10$.
The total destruction of the cotton samples $(10 \mathrm{~g})$ - i.e. when the cotton samples were totally converted into microfibrilar material - was obtained after $6 \mathrm{~h}$ of treatment at a high level of mechanical agitation (Rotawash +15 discs) and an enzyme dosage of $100 \mathrm{mg} / \mathrm{g}$ (Figure 5). When the conditions of Figure 1 were applied to a cotton sample of $10 \mathrm{~g}$, the total destruction of the sample was not observed. However, the enzyme dosage of $100 \mathrm{mg} / \mathrm{g}$ resulted in a significant increase in the fabric area (from 14 to $630 \mathrm{~cm}^{2}$ ), which means that the amount of enzyme available on a surface area basis was lower, thereby clarifying the low hydrolysis obtained: there was microfibrillar material production, but the main fabric structure remained intact. This result shows that bath ratio is also an important parameter in this enzymatic process. However, the proper combination of enzyme dosage, mechanical agitation and treatment time is essential to achieving the destruction of the fiber structure of textiles. Morgado et al. (2000) found that the crystallinity was not changed during the treatment at a high level of agitation. The integrity of the microfibrilar material we produced (Figure 4c) seems to support these findings by Morgado et al. (2000). 

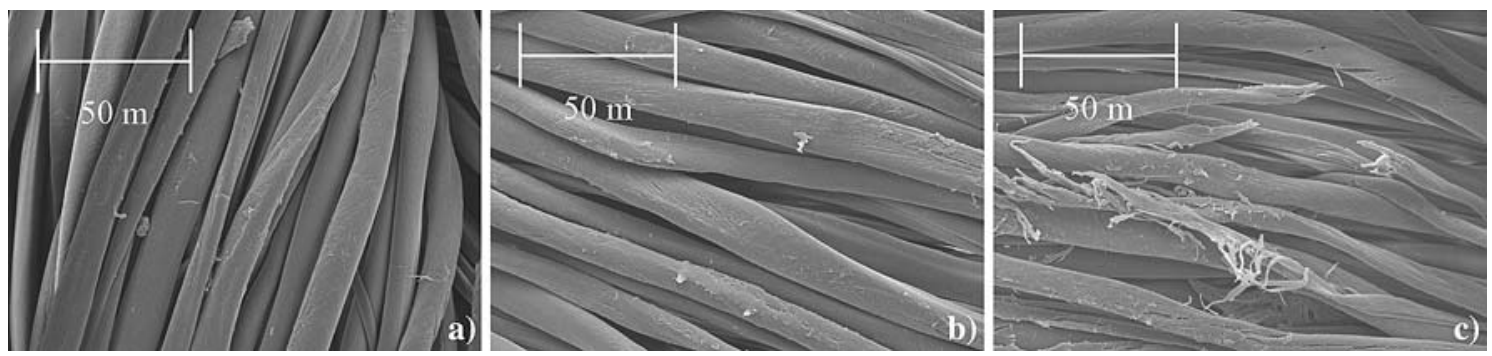

Figure 3. SEM pictures of the cotton sample without treatment (a) and treated with an enzyme dosage of $200 \mathrm{mg} / \mathrm{g}$ and with, no discs (b) and discs (c).
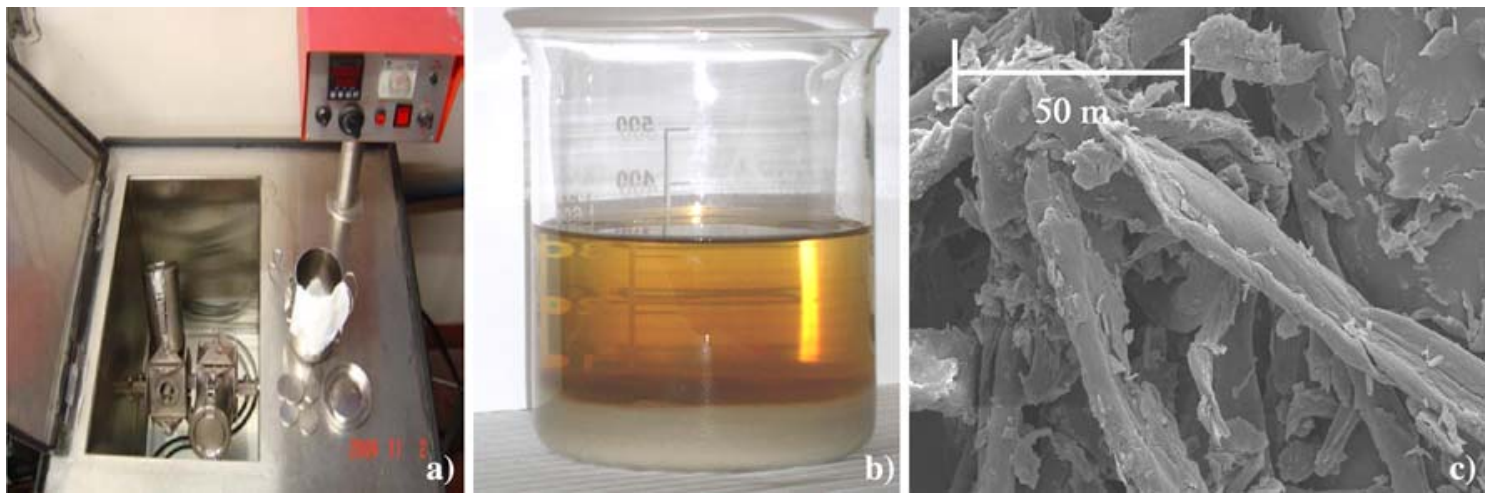

Figure 4. Rotawash machine where the treatments were performed (a), cotton powder formed ( b), and the SEM picture of the cotton powder formed during the enzymatic treatments (c).

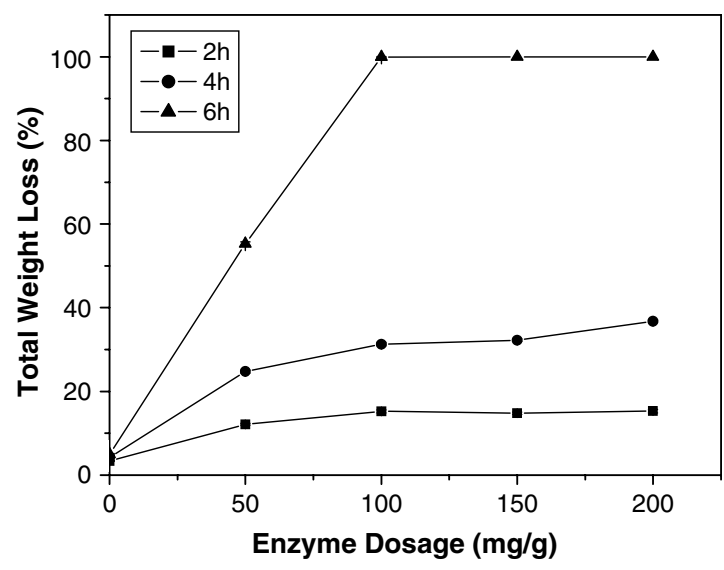

Figure 5. Variation in the total weight loss (\%) of the samples as a function of enzyme dosage $(\mathrm{mg} / \mathrm{g})$ and duration of treatment (2, 4 and $6 \mathrm{~h}$ ), at high levels of mechanical agitation (Rotawash +15 discs), a bath ratio of 1:25 and a temperature of $50{ }^{\circ} \mathrm{C}$.

\section{Treatment of polyester/cotton blend}

One of the objectives of this investigation was to determine the appropriate treatment conditions that were achieve the total hydrolysis of cellulose in a $100 \%$ cotton fabric. These were determined to be a long treatment time (up to $6 \mathrm{~h}$ ), a high level of mechanical agitation (Rotawash +15 discs) and an enzyme dosage of $100 \mathrm{mg} / \mathrm{g}$. We applied these conditions to our polyester/cotton blend, and the results are presented in Figure 6. The degree of cellulose hydrolysis from the blend was significantly smaller, even though there was an increase in the treatment time $(9 \mathrm{~h})$ and enzyme dosage $(200 \mathrm{mg} / \mathrm{g})$. When the optimal conditions obtained for $100 \%$ cotton samples were applied to the polyester/cotton fabric, the maximum weight loss obtained was $45 \%$ (results not shown). The cellulose hydrolysis of the blend remained relatively constant as the treatment continued; therefore, the total weight loss of the samples would not increase 


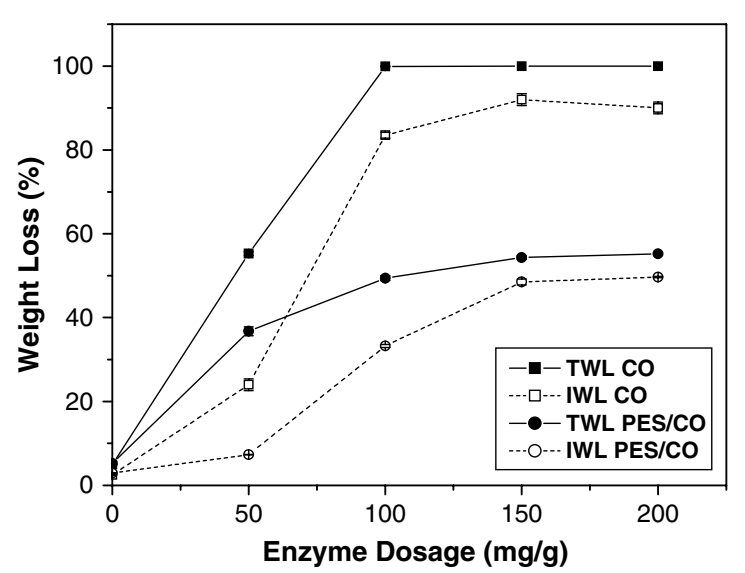

Figure 6. Variation in total $(T W L)$ and insoluble $(I W L)$ weight loss of cotton $(C O)$ and polyester/cotton $(P E S / C O)$ samples at an enzyme dosage after $6(\mathrm{CO})$ and $9(\mathrm{PES} / \mathrm{CO})$ hours of treatment, a high level of mechanical agitation (Rotawash +15 discs), a bath ratio of $1: 25$ and a temperature of $50{ }^{\circ} \mathrm{C}$.

with the increase in treatment time, mechanical agitation and enzyme dosage.

As already shown, cellulose degradation is accomplished by the production of insoluble material. Figure 6 is a representation of the insoluble weight loss of the cotton and polyester/ cotton samples. There is an apparent direct relationship between the production of insoluble material and the total weight loss. The amount of insoluble material produced during the cellulose degradation from the polyester/cotton sample is approximately twofold smaller than that from the $100 \%$ cotton sample.

Assuming that cellulose from the cotton fabric has the same fine structure as that from the polyester/cotton fabric blend, the total weight loss effected by the cellulase treatment should be similar under the same conditions. However, this was not observed since a considerably smaller proportion of the cellulosic part was removed from the blend than from the $100 \%$ cotton fabric. Cavaco-Paulo (1998) and Cortez et al. (2001) verified that microscopic factors, such as fabric construction, play an important role in determining the levels of weight loss obtained in cellulase treatments carried out at high levels of mechanical agitation. These researchers proved that fabric constructions which lead to a more exposed fiber surface area will be more easily degraded; that is, a knitted fabric leads to higher yields of weight loss than woven struc- tures. The presence of polyester in a fabric blend will considerably reduce the surface area of the cotton fibers exposed to enzyme attack in macroscopic terms. This is particularly important when mechanical agitation is present, as was the case in our experiments. Cellulase enzymes seem to adsorb on polyester fibers in a competitive manner in the presence of cotton, under the same conditions described in Figure 6. Approximately 30\% more protein was adsorbed on the polyester fibers than on the cotton fibers, as determined by the protein staining method described by Andreaus et al. (1999). This fact also contributes an explanation of the lower weight loss obtained in the blended fabric.

Figure 7 presents the SEM pictures for the polyester/cotton samples, both without treatment and treated with cellulase and sulfuric acid. The sample treated with $75 \%(\mathrm{v} / \mathrm{v})$ sulfuric acid solution is called the 'skeleton', as the cellulose was totally removed from this sample due to the ability of the acid to dissolve the cellulose. Some cotton fibers still remain in the cellulose-treated sample; this is visible as the smaller inter-yarn space on this picture (Figure 7b). However, the result obtained was very similar to the samples treated with acid.

\section{Physical tests}

The increase in total weight loss will decrease the flexural rigidity $(G)$ and the breaking strength. However, the bending stiffness (Figure 8a) of the 'skeleton' is high. This could be explained by the increase in the stiffness of the fiber surface due to the acidic treatment. The enzymatic treatment causes the 'polishing' of the fiber's surface, which decreases the bending stiffness. We found no major difference between the bending length of the warp and weft . The maximum force was higher for the warp (Figure 8b). The cellulase-treated sample in which there was a higher activity of enzyme (55\% of total weight loss) lost $30 \%$ of its initial strength on the warp and weft, whereas the 'skeleton' retained $21 \%$ of its initial strength on the warp and $18 \%$ on the weft.

\section{Conclusions}

Cotton fibers can be completely converted into microfibrillar material by the combined action of 

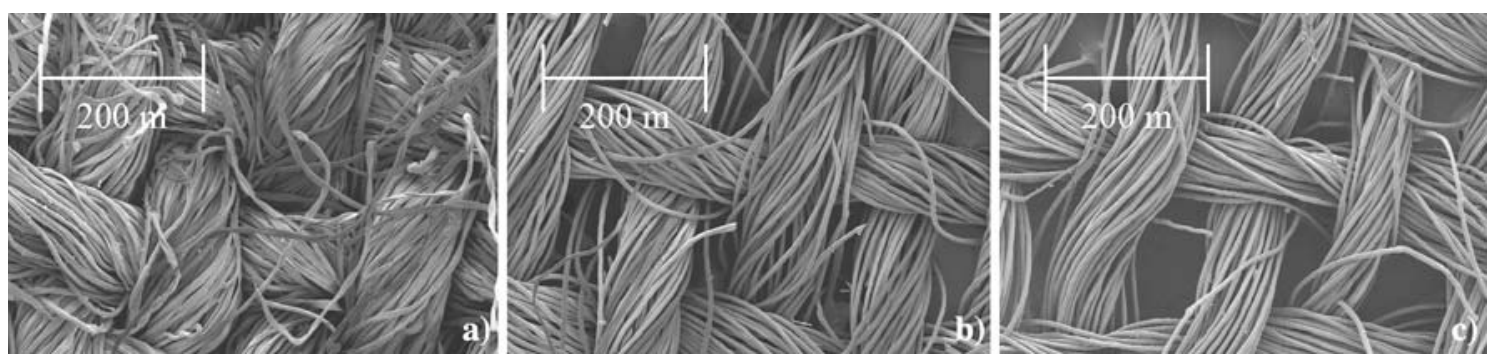

Figure 7. SEM pictures of the polyester/cotton sample without treatment (a) treated with Cellusoft L (b) and treated with sulfuric acid (c). Amplification: $100 \times$.
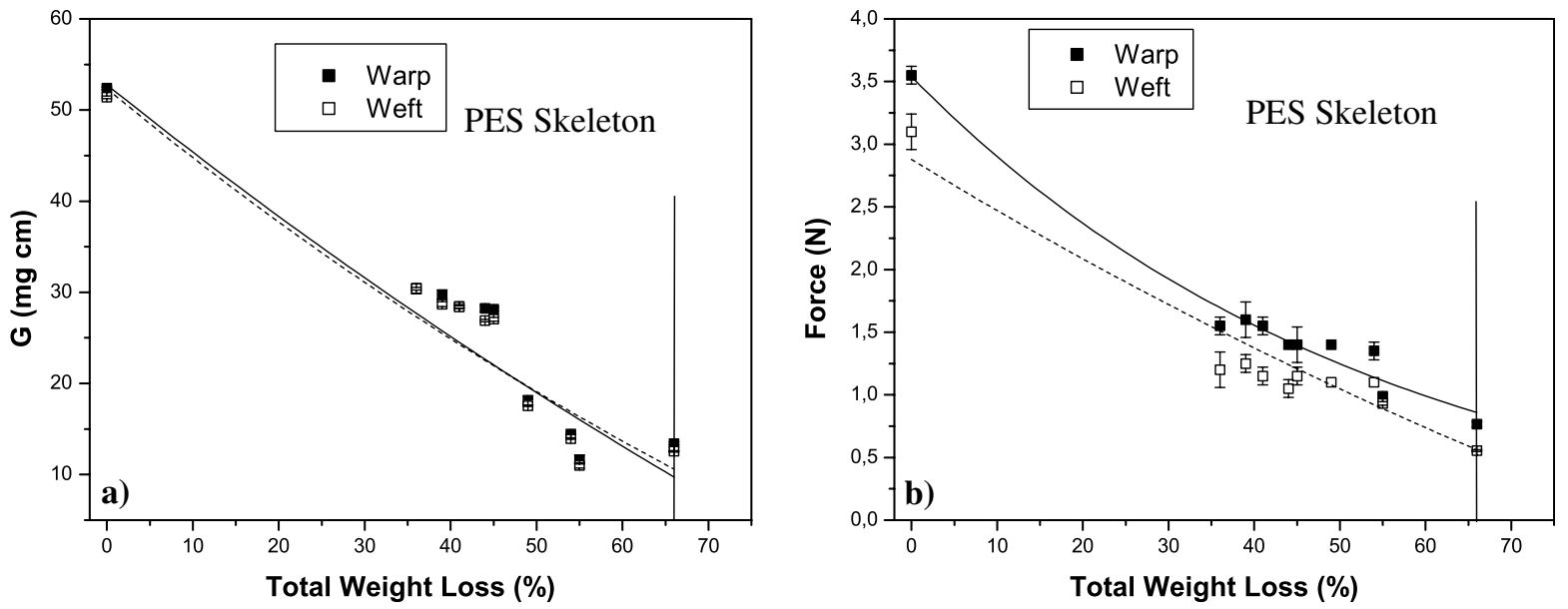

Figure 8. Variation in the flexural rigidity, $G(\mathrm{mg} / \mathrm{cm})(\mathrm{a})$, and the force, $N$,(b) of the fabric with total weight loss $(\%)(P E S$ Polyester). Straight line (warp) and Dash line (weft).

enzyme hydrolysis and strong mechanical effects in short periods of time. The production of insoluble material is dependent on the level of beating effects present inside the treatment pots.

The results of this investigation show that the combined action of mechanical effects and enzymatic action can be used for the production of lightweight polyester fabrics as well as for the production of microfibrillar cellulosic material. However, high concentrations of cellulase should be used.

\section{References}

Aizenshtein E.M. 2004. World chemical fiber and thread production in 2003. Fiber Chem. 36: 467-482.

Andreaus J., Azevedo H. and Cavaco-Paulo A. 1999. Effects of temperature on the cellulose binding ability of cellulase enzymes. J. Mol. Catal. B: Enzyme 7: 233-239.
Béguin P. 1990. Molecular biology of cellulose degradation. Annu. Ver. Microbiol. 44: 219-248.

Boisset C., Pétrequin C., Chanzy H., Henrissat B. and Schülein M. 2001. Optimized mixtures of recombinant Humicola insolens cellulases for the biodegradation of crystalline cellulose. Biotechnol. Bioeng. 72: 339-345.

Bradford M. 1976. A rapid and sensitive method for the quantification of microgram quantities of protein utilizing the principle of protein-dye binding. Anal. Biochem. 72: $248-254$.

Camacho F., González-Tello E., Jurado E. and Robles A. 1996. Microcrystalline cellulose hydrolysis with concentrated sulphuric acid. J. Chem. Technol. Biotechnol. 67: 350-356.

Cavaco-Paulo A. 1998. Mechanism of cellulase action in textile processes. Carbohydr. Polym. 37: 273-277.

Cavaco-Paulo A., Almeida L. and Bishop D. 1996. Effects of agitation and endoglucanase pre-treatment on the hydrolysis of cotton fabrics by a total cellulase. Text. Res. J. 66: 287-294.

Clarke A.J. 1997. Biodegradation of Cellulose: Enzymology and Biotechnology. Technomic, Lancaster, PA.

Cortez J.M., Ellis J. and Bishop D.P. 2001. Cellulase finishing of woven, cotton fabrics in jet and winch machines. J. Biotechnol. 89: 239-245. 
Foreman P., Brown D., Dankmeyer L., Dean R., Diener S., Dunn-Coleman N., Goedegebuur F., Houfek T., England G., Kelley A., Meerman H., Mitchell T., Mitchinson C., Olivares H., Teunissen P., Yao J. and Ward M. 2003. Transcriptional regulation of biomass-degrading enzymes in the filamentous fungus Trichoderma reesei. J. Biol. Chem. 278: 31988-31997.

Guimarães B.G., Souchon H., Lytle B.L., Wu J.H.D. and Alzari P.M. 2002. The structure and catalytic mechanism of cellobiohydrolases CelS, the major enzymatic component of the Clostridium thermocellum cellulosome. J. Mol. Biol. 230: $587-596$.

Jeoh T., Wilson D.B. and Walker L.P. 2002. Cooperative and competitive binding in synergistic mixtures of Thermobifida fuscas cellulases Cel5A, Cel5B and Cel9A. Biotechnol. Prog. 18: 760-769.

Mansfield S.D., Mooney C. and Saddler J.N. 1999. Substrate and enzyme characteristics that limit cellulose hydrolysis. Biotechnol. Prog. 15: 804-816.

Mäntylä A., Paloheimo M. and Suominen P. 1998. Industrial mutants and recombinant strains of Trichoderma reesei. In: Harman G.E. and Kubicek C.P. (eds), Trichoderma and Gliocladium, Vol. 2. Taylor \& Francis, London, pp. 291-309.

Miettinen-Oinonen A., Paloheimo M., Lantto R. and Suominen P. 2005. Enhanced production of cellobiohydrolases in Trichoderma reesei and evaluation of the new preparations in biofinishing of cotton. J. Biotechnol. 116: 305-317.
Morgado J., Cavaco-Paulo A. and Rousselle M.-A. 2000. Enzymatic treatment of Lyocell - clarification of deppiling mechanisms. Text. Res. J. 70: 696-699.

Murashima K., Kosugi A. and Doi R.H. 2002. Synergistic effects on crystalline cellulose degradation between cellulosomal cellulases from Clostridium cellulovorans. J. Bacteriol. 184: $5088-5095$.

Parsiegla G., Juy M., Reverbel L.C., Tardif C., Bélaich J.-P., Driguez H. and Haser R. 1998. The crystal structure of processive endocellulase CelF of Clostridium cellulolyticum in complex with a thiooligosaccharide inhibitor at 20 A resolution. EMBO J. 17: 5551-5562.

Penttilä M. 1998. Heterologous protein production in Trichoderma. In: Harman G.E. and Kubicek C.P. (eds), Trichoderma and Gliocladium, Vol. 2. Taylor \& Francis, London, pp. 365-382.

Teeri T.T. 1997. Crystalline cellulose degradation: new insight into the function of cellobiohydrolases. Trends Biotechnol. 15: $160-167$.

Tomme P., Warren R.A.J. and Gilkes N.R. 1995. Cellulose hydrolysis by bacteria and fungi. Adv. Microb. Physiol. 37: $1-81$. 